\title{
BMJ Open Quality How do we encourage a change of behaviour around colleagues taking breaks?
}

\author{
Anna Baverstock (D) , ${ }^{1}$ Lorna Stewart, ${ }^{2}$ Claire White ${ }^{3}$
}

To cite: Baverstock A, Stewart L, White C.

How do we encourage a change of behaviour around colleagues taking breaks? BMJ Open Quality 2020;9:e000968. doi:10.1136/ bmjoq-2020-000968

Received 16 March 2020 Revised 27 April 2020 Accepted 18 May 2020
Check for updates

(c) Author(s) (or their employer(s)) 2020. Re-use permitted under CC BY-NC. No commercial re-use. See rights and permissions. Published by BMJ.

${ }^{1}$ Paediatrics, Musgrove Park Hospital, Taunton, UK

${ }^{2}$ Clinical Psychologist \& Deputy Manager, Improvement Team, Musgrove Park Hospital, Taunton, UK

${ }^{3}$ Data Specialist and Advisor, Improvement Team, Musgrove Park Hospital, Taunton, UK

Correspondence to Dr Anna Baverstock; anna.baverstock@tst.nhs.uk

\section{BACKGROUND}

There is increasing evidence that in order to ensure colleagues are able to deliver safe, high-quality care from the beginning to the end of a shift we must prioritise breaks. ${ }^{1-3}$ Taking a break can include eating or having a drink, a physical rest or for some a walk or fresh air. Regular rest is essential, especially when busy or working overnight and for reducing work-related stress.

There is growing support and enthusiasm for prioritising colleague breaks in order to simultaneously improve colleague wellbeing (particularly work-related stress), and to therefore also improve patient safety. Within NHS Trusts there have been some high-profile campaigns started, we believe at Guys and St Thomas'. ${ }^{1}$ The British Medical Association (BMA) are also launching their \#giveusabreak campaign. ${ }^{2}$ The Health Education England (HEE) National Health Service (NHS) Mental Wellbeing report highlights this. ${ }^{3}$

Across our NHS Trust we have relaunched our HALT (are you Hungry, Angry, Late or Tired?) campaign with poster and enhanced communications; baseline data indicated poor levels of break-taking ( $44 \%$ of colleagues 'always' or 'mostly' take a break, June 2019) and high levels of stress $(52 \%$ of colleagues self-reported that they had not felt unwell as a result of work-related stress, April 2019). We recognised that in order to change behaviour around a break culture, quality improvement was needed.

\section{AIM}

One improvement aim was focused on for this paper:

1. To increase colleague well-being by increasing the number of colleagues reporting that they 'always' or 'mostly' take a break from $44 \%$ to $70 \%$ by October 2020.

\section{METHODS}

As part of the Trust Wellbeing Conference (June 2019) we ran four HALT workshops. This included background information around the positive benefits of taking a break and an introduction to mindfulness session. We then looked at barriers and enablers to taking a break. We captured quantitative and qualitative baseline data prior to the workshop and collected postconference data from the representative sample of colleagues. Subsequently we have captured regular data to establish if changes in break-taking behaviour have been sustained. Our process and outcome measures were:

1. How regularly are colleagues taking a break? ('always', 'mostly', 'sometimes', 'occasionally' and 'never').

2. Percentage of colleagues self-reporting work-related stress (not described further in this paper).

\section{RESULTS}

Ninety-one colleagues attended our four workshops. Figure 1 indicates the results of the measures of break-taking.

Barriers and enablers to taking a break were elicited from the 91 participants and are summarised as in table 1.

Thematic analysis of workshop conversations revealed that enablers and barriers to breaks come from individual, team and organisational factors (figure 2).

\section{DISCUSSION}

Our conference workshop has shown that although intention to take a break is high ( $87 \%$ of colleagues), there are many barriers that need to be considered for colleagues. Alongside this, there are enablers that facilitate a break culture. Changes are needed as individuals but perhaps more importantly as teams and organisations to enable all colleagues to feel empowered to take their 


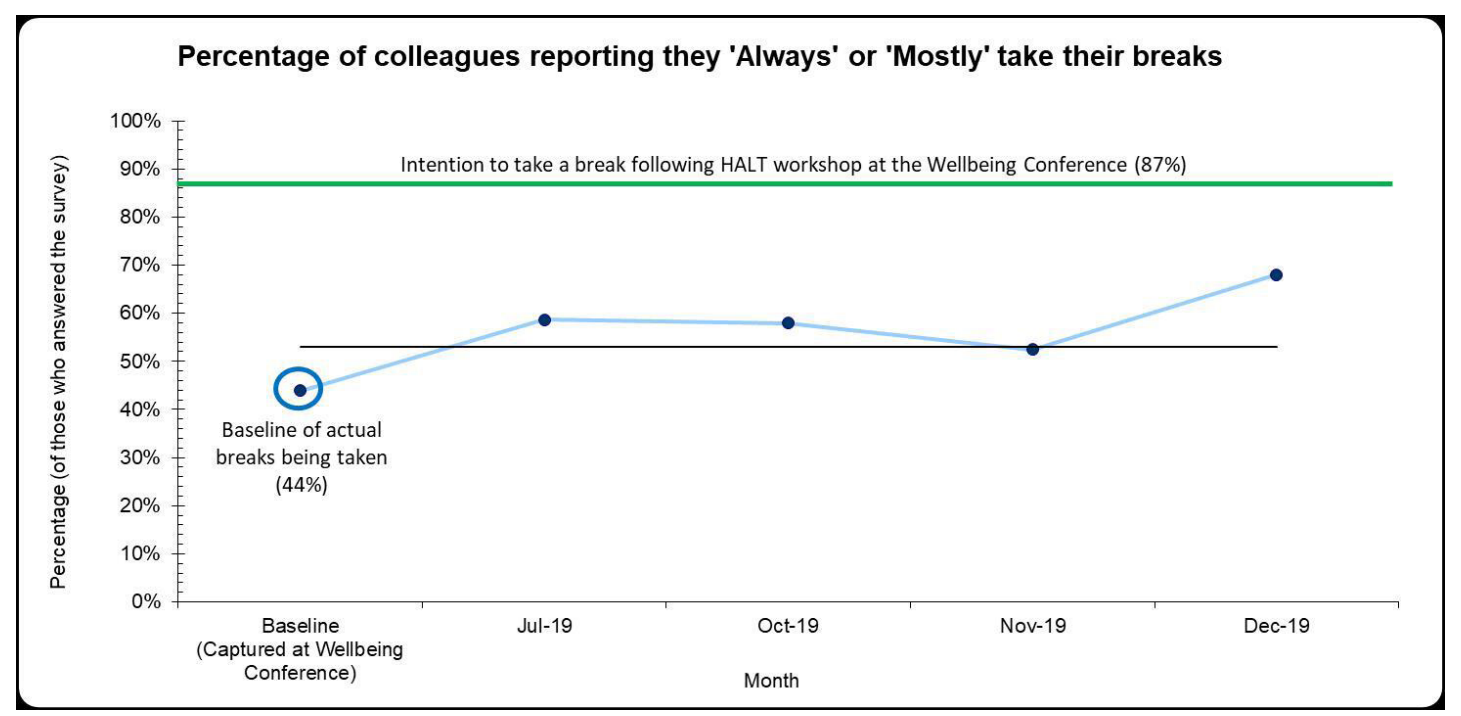

Figure 1 Results of the measures of break-taking. HALT, Hungry, Angry, Late or Tired.

breaks. The reality of current working conditions is that unless some of the team and organisational barriers to breaks are addressed, we are unlikely to achieve or maintain individual behaviour changes for all colleagues. The environment needs to be prioritised in order for clinical staff to be able to 'have my break away from the patients I have just seen in clinic' and 'away from my desk otherwise I will end up working'. The importance of senior leaders as role models should also not be underestimated.

We have used the deep understanding of the barriers to develop further change ideas in four areas across the trust (acute hospital, community hospital, community services and mental health services) where work-related stress was high, for future improvements.

\section{CONCLUSION}

We found that an educational workshop provided the additional motivation needed to change intention to take a break ( $87 \%$ of colleagues), by facilitating a discussion around enablers and barriers to taking a break. Four months later, $13 \%$ more colleagues reported that they 'always' or 'mostly' took a break before the workshop. Aspirational figures to take a break does not translate into actual due to the effects of individual, team and organisational barriers. We must continue to encourage senior role modelling, provision of the correct environment and a change of work schedules to enable the change required as individuals, in both our teams and wider organisation.

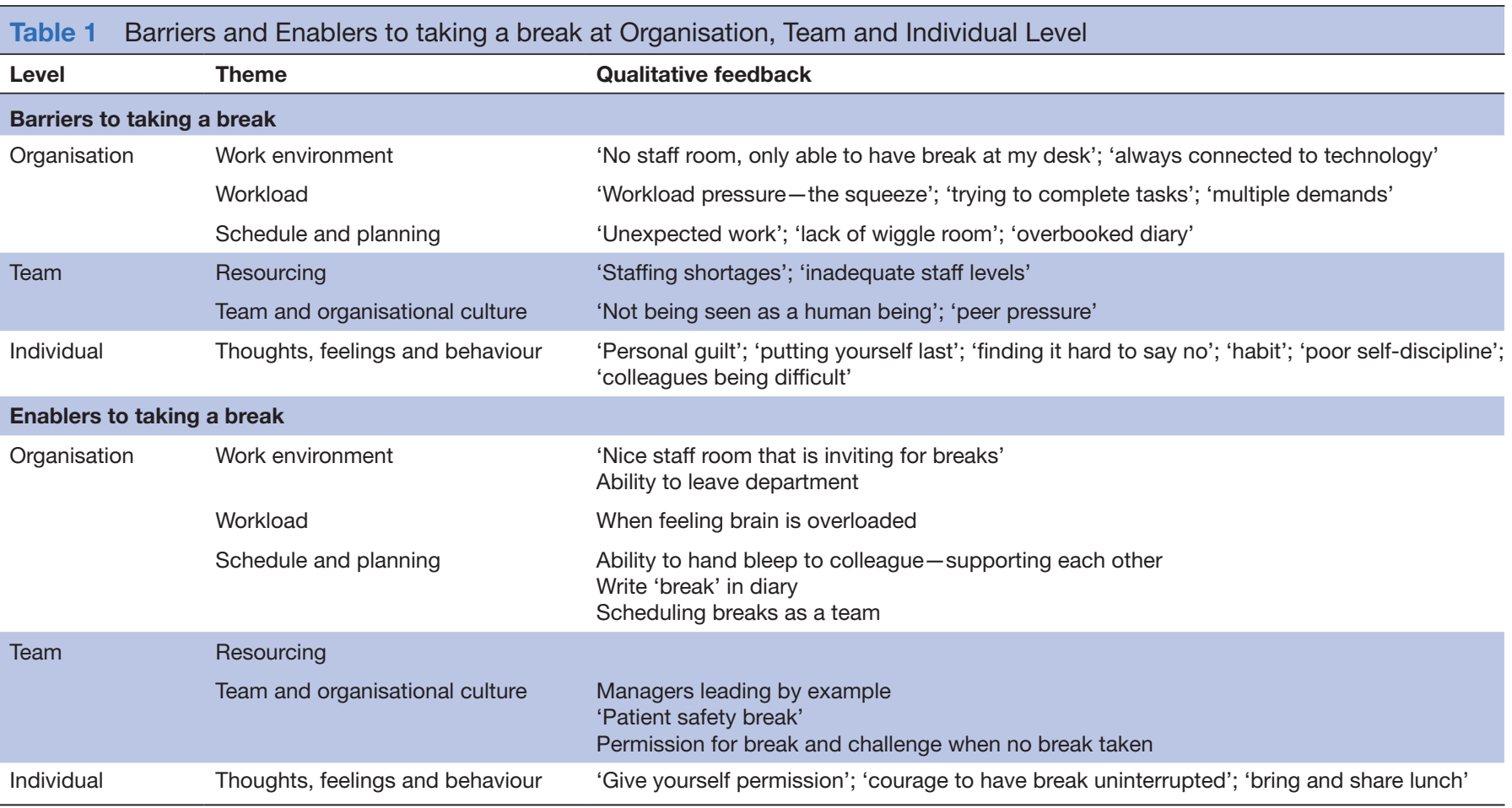




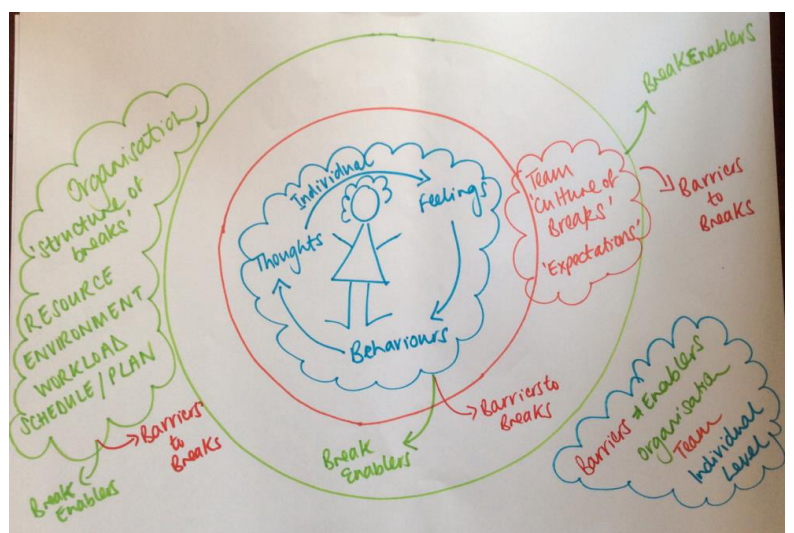

Figure 2 Thematic analysis of workshop conversations revealed that enablers and barriers to breaks come from individual, team and organisational factors.

Twitter Anna Baverstock @anna_annabav

Contributors All authors were involved in design, analysis and write up of project. LS and $A B$ facilitated the workshops. CW led the data analysis with $L S$ and $A B$.

Funding The authors have not declared a specific grant for this research from any funding agency in the public, commercial or not-for-profit sectors.
Competing interests None declared.

Patient and public involvement Patients and/or the public were not involved in the design, or conduct, or reporting or dissemination plans of this research.

Patient consent for publication Not required.

Provenance and peer review Not commissioned; externally peer reviewed.

Data availability statement Data are available upon request.

Open access This is an open access article distributed in accordance with the Creative Commons Attribution Non Commercial (CC BY-NC 4.0) license, which permits others to distribute, remix, adapt, build upon this work non-commercially, and license their derivative works on different terms, provided the original work is properly cited, appropriate credit is given, any changes made indicated, and the use is non-commercial. See: http://creativecommons.org/licenses/by-nc/4.0/.

ORCID iD

Anna Baverstock http://orcid.org/0000-0002-3257-3298

\section{REFERENCES}

1 Guy's and St Thomas NHS Foundation Trust. Guy's and St Thomas' staff encouraged to take regular breaks in new HALT campaign. Available: https://www.guysandstthomas.nhs.uk/news-and-events/ 2017-news/march/20170317-halt-campaign.aspx

2 Chatfield C, Rimmer A. Give us a break. BMJ 2019;364:I481.

3 NHS Health Education England. Mental wellbeing report. Available: https://www.hee.nhs.uk/our-work/mental-wellbeing-report 